\title{
Desenvolvimento da compreensão oral em Português Língua Segunda com recurso a materiais semi-autênticos
}

\author{
Development of oral comprehension in Portuguese as a Second \\ Language using semi-authentic materials
}

\section{Desarrollo de la comprensión oral en Portugués como Lengua Segunda utilizando materiales semi-auténticos}

\author{
Yanping Tang ${ }^{1}$ (i) https://orcid.org/0000-0001-7047-2896
}

\begin{abstract}
RESUMO: A compreensão oral assume um papel crucial no desenvolvimento da competência comunicativa de uma língua estrangeira. É também considerada como a competência mais difícil de aprender devido à sua natureza intrínseca. Para o ensino-aprendizagem da compreensão oral na sala de aula, os materiais didáticos de compreensão oral constituem um elemento indispensável na realização de atividades. Nesse sentido, com recurso a metodologia de investigação-ação, foi desenvolvido um projeto junto de alunos de nível A1.2, no âmbito do estágio pedagógico do Mestrado em Português Língua Segunda/Língua Estrangeira, da Faculdade de Letras da Universidade do Porto, com o objetivo principal de desenvolver a compreensão oral dos aprendentes de Português Língua Segunda, através da criação dos recursos semi-autênticos. Analisando os resultados obtidos, podemos afirmar que, i.) a aplicação do modelo da aula centrada na compreensão oral - pré-atividade, atividade e pós-atividade - contribui não só para o sucesso da atividade de compreensão oral, como promove também o desenvolvimento de outras competências, sobretudo a competência linguística nas vertentes da expressão e interação oral; ii.) os materiais áudio e audiovisuais criados ao longo da intervenção pedagógica constituem uma mais-valia para o enriquecimento de materiais didáticos destinados aos aprendentes de Português Língua Segunda.
\end{abstract}

PALAVRAS-CHAVE: Compreensão oral. Materiais didáticos. Português Língua Segunda.

\begin{abstract}
Oral comprehension plays a crucial role in the development of the communicative competence of a foreign language. It is also considered to be the most difficult skill to learn due to its intrinsic nature. When it comes to the teaching and learning of oral comprehension in the classroom, the didactic materials are an indispensable element in carrying out activities. In this
\end{abstract}

\footnotetext{
${ }^{1}$ Mestre em Português Língua Segunda/Língua Estrangeira pela Universidade do Porto. E-mail: daliatang@163.com
} 
sense, using action research methodology, a project was developed with A1.2 level students, within the scope of the pedagogical internship of the Masters in Portuguese as Second Language/Foreign Language, of the Faculty of Arts of University of Porto, with the main objective of developing the oral comprehension of learners of Portuguese as a Second Language, through the creation of semi-authentic resources. After analysing the results, we can conclude that: i.) the application of the class model centred on oral comprehension - pre-activity, activity and postactivity - contributes not only to the success of the activity of oral comprehension, but also promotes the development of other competences, especially linguistic competence in the areas of oral expression and interaction; ii.) the audio and audiovisual materials created during the pedagogical intervention constitute an asset for the enrichment of didactic materials for the learners of Portuguese as a Second Language.

KEYWORDS: Oral comprehension. Didactic materials. Portuguese as a Second Language.

RESUMEN: La comprensión oral juega un papel crucial en el desarrollo de la competencia comunicativa en una lengua extranjera. También se considera la habilidad más difícil de aprender debido a su naturaleza intrínseca. Para la enseñanza y aprendizaje de la comprensión oral en el aula, los materiales didácticos de comprensión oral son un elemento indispensable en la realización de las actividades. En este sentido, utilizando la metodología de investigación-acción, se desarrolló un proyecto con estudiantes de nivel A1.2, en el marco de la pasantía pedagógica de la Maestría en Portugués como Lengua Segunda/Lengua Extranjera, en la Facultad de Artes de la Universidad de Porto, con el objetivo principal de desarrollar la comprensión oral de los estudiantes de Portugués como Lengua Segunda, a través de la creación de recursos semiauténticos. Analizando los resultados obtenidos, podemos afirmar que, i.) La aplicación del modelo de la clase centrada en la comprensión oral - pre-actividad, actividad y post-actividad contribuye no solo al éxito de la actividad de comprensión oral, sino también promueve el desarrollo de otras habilidades, especialmente la competencia lingüística en términos de expresión e interacción orales; ii.) los materiales de audio y audiovisuales creados durante la intervención pedagógica constituyen un activo para el enriquecimiento de los materiales didácticos destinados a los estudiantes de Portugués como Lengua Segunda.

PALABRAS CLAVE: Comprensión oral. Materiales didácticos. Portugués como Lengua Segunda.

\section{Introdução}

O presente estudo é o resultado da investigação e intervenção pedagógicodidática, desenvolvidas no âmbito do Mestrado em Português Língua Segunda/Língua Estrangeira, da Faculdade de Letras da Universidade do Porto (FLUP). Tem como objetivo principal abordar o desenvolvimento da competência da compreensão oral dos alunos de Português Língua Segunda² (PLS), com recurso a materiais semi-autênticos.

\footnotetext{
2 No âmbito da didática de línguas, os conceitos de língua segunda (LS/L2) e língua estrangeira (LE) são ambos para designar a aprendizagem de uma língua não materna. De acordo com Stern (1983 apud LEIRIA, 2004, p. 1), o termo LS é aplicado para "classificar a aprendizagem e o uso de uma língua não-nativa dentro de fronteiras territoriais em que ela tem uma função reconhecida" e o termo LE é usado para "classificar a aprendizagem e o uso em espaços onde essa língua não tem qualquer estatuto sociopolítico". Ou seja, a distinção de designação entre LS e LE está sujeita ao estatuto sociopolítico que a língua tem no contexto de aprendizagem e uso. Tendo em conta o contexto de aprendizagem em que se encontram os aprendentes de Português considerados do presente projeto, que é situação
} 
A compreensão oral (CO) é uma das competências mais essenciais da aprendizagem de uma língua segunda (LS)/língua estrangeira (LE). Também é considerada como a competência mais difícil de aprender devido à sua natureza intrínseca. Para potenciar ao máximo o desenvolvimento da CO, o professor precisa de conhecer em profundidade as suas características e os processos envolvidos nesta competência. Os materiais de CO, como suporte de input, merecem também uma abordagem didática relativa ao seu uso nas aulas de línguas. Tendo em conta a importância da competência comunicativa no ensino-aprendizagem de línguas, os materiais autênticos que apresentam o uso real da língua nas situações comunicativas devem ser privilegiados. Porém, as suas características também dificultam a sua aplicação nos níveis iniciais de aprendizagem de LS/LE, como era o caso do público-alvo do nosso estudo. Nesta situação, torna-se indispensável a criação de materiais que se aproximem dos discursos verossímeis e se adequem ao contexto de ensino e perfil dos alunos em causa.

Para alcançar o nosso objetivo, iniciamos com a abordagem acerca da compreensão oral no ensino-aprendizagem de LS/LE, nomeadamente as suas características e os processos envolvidos. Seguidamente, versamos sobre os materiais autênticos e criados para o desenvolvimento da compreensão oral. Procedemos posteriormente à descrição da intervenção pedagógico-didática realizada na FLUP, dando um exemplo de uma unidade didática centrada no desenvolvimento da CO. Por fim, analisamos os resultados da intervenção pedagógico-didática e apresentamos as conclusões do nosso estudo.

\section{Compreensão oral no ensino-aprendizagem de línguas estrangeiras}

$\mathrm{Na}$ aprendizagem de uma LS e LE, a compreensão oral assume-se como uma competência fundamental para a comunicação. Além disso, considera-se que os aprendentes de LS/LE dedicam mais de 50 por cento do tempo de utilização da línguaalvo à compreensão oral (NUNAN, 1997). Efetivamente, nas situações comunicativas da vida real, passamos muito tempo a ouvir os discursos orais dos outros, seja para obtermos informações na situação transacional, seja para estabelecermos relações sociais 
na situação interacional. Ouvir rádio, ver televisão, assistir a palestras, a aulas, são alguns exemplos do primeiro caso, no qual o ouvinte só precisa de ouvir e compreender o que é dito pelo falante, enquanto que, no segundo, destaca-se a troca de turnos de fala entre o ouvinte e o falante, tais como pedir ajuda a um estranho na rua, conversar com os amigos e a família, fazer compras, etc.

Sendo uma das quatro habilidades básicas (ouvir, falar, ler, escrever) de língua, a compreensão oral também está interligada com outras competências, sobretudo a produção oral. Field (2009) afirma que uma necessidade a longo prazo dos aprendentes de LE reside em interagir oralmente com outros falantes da língua-alvo. Nas palavras de Rost (2011, p. 1), "there is no spoken language without listening"3, salientando assim este autor a relação interdependente entre a compreensão e expressão orais. Aliás, Nunan (2002, p. 239) refere também que "without understanding input at the right level, any learning simply cannot begin. Listening is thus fundamental to speaking"4. Daí percebe-se que, para o desenvolvimento de competências orais, a compreensão não é menos importante do que a expressão. Além disto, como uma fonte de input da línguaalvo, a compreensão oral providencia a oportunidade de expor os aprendentes aos discursos orais das diversas situações comunicativas em língua-alvo, contribuindo para o desenvolvimento de output, especialmente da produção oral e escrita.

Não obstante a sua importância, vários autores (FIELD, 2009; NATION; NEWTON, 2009; NUNAN, 1997, 2002) apontam que a compreensão oral é a mais negligenciada das quatro habilidades na sala de aula de línguas, especialmente quando as horas letivas são limitadas: é comum que a parte da compreensão oral seja reduzida e desvalorizada. Para além disto, em termos dos estudos e investigações, a metodologia sobre as aulas de compreensão oral tem sido pouco discutida e investigada, devido aos fatores históricos e à natureza da compreensão oral.

No que diz respeito ao desenvolvimento histórico, apenas desde a década de 60 do século XX e com a chegada da Abordagem Comunicativa é que a compreensão oral passou a ser considerada uma competência a se desenvolver no ensino-aprendizagem de línguas, pois até então tinha sido praticada apenas a fim de auxiliar principalmente o

\footnotetext{
3 Trecho traduzido: "Não há língua falada sem ouvir" (ROST, 2011, p. 1, tradução nossa).

${ }^{4}$ Trecho traduzido: "Sem compreender o input no nível certo, qualquer aprendizagem simplesmente não pode começar. Ouvir é, portanto, fundamental para falar" (NUNAN, 2002, p. 239, tradução nossa).
} 
ensino de gramática (FIELD, 2009). Já relativamente à natureza da compreensão oral, a audição é uma atividade invisível que ocorre na mente dos indivíduos, o que impede a observação direta sobre este processo e, portanto, torna difícil a investigação. Field (2009) defende que a compreensão oral é a mais interiorizada das quatro competências principais, comparando ainda esta com a compreensão escrita, que apesar de ser também interiorizada, pode ser observada através dos movimentos da vista do leitor a mover-se nas páginas, o chamado "eye tracking", que pode ser objetivamente medido. Quanto à compreensão oral, não há maneira de saber se o ouvinte está a ouvir ou se está a focarse no que é dito. Desta maneira, a única evidência disponível para saber se o aprendente compreende é indireta, com recurso às perguntas e tarefas de compreensão.

Por causa da sua natureza, a compreensão oral é, tradicionalmente, considerada um processo passivo, no qual o ouvinte apenas ouve a informação transmitida pelo falante. No entanto, a audição não representa mesmo a compreensão oral; para Field (2009, p. 29), "comprehension is certainly the end product of listening"5. Cada vez mais estudos recentes reconhecem a compreensão oral como um processo ativo e interpretativo (RICHARDS, 2008), pelo que em vez de receber inalteradamente a mensagem transmitida, o ouvinte interpreta e constrói o significado da informação em função do contexto (LYNCH; MENDELSOHN, 2002 apud NATION; NEWTON, 2009), dos seus conhecimentos linguísticos e dos seus conhecimentos do mundo.

\section{Processos de compreensão oral}

No âmbito de estudos sobre o processo cognitivo da compreensão oral, as duas perspetivas de bottom-up e top-down são as mais reconhecidas pelos investigadores desta área. Segundo Nunan (2002), Richards (2008) e Nation e Newton (2009), de forma genérica, o processo de bottom-up assume que a compreensão oral é um processo de descodificar os sons ouvidos numa sequência linear, das unidades menores até ao texto completo. 0 processo de top-down pressupõe que o ouvinte constrói ativamente 0 significado transmitido pelo falante, usando os conhecimentos prévios sobre o contexto e a situação comunicativa para compreender o que o falante diz.

Em vez das perspetivas de bottom-up top-down, Field (2009) propõe o processo de descodificação e construção de sentido para descrever o processo de compreensão

\footnotetext{
5 Trecho traduzido: "A compreensão é certamente o produto final da audição" (FIELD, 2009, p. 29, tradução nossa).
} 
oral. A razão pela qual o autor adota estes dois termos está relacionada com a seguinte opinião:

[...] Because listening is online, we cannot assume that there is an easy "bottom-up" progression from sounds to syllables to words to phrases. And the "top-down" uses of context can serve two very different purposes: to compensate for gaps in understanding or to enrich a fully decoded message (FIELD, 2009, p. 132).

Para o autor, um ouvinte, tanto em língua materna ou língua estrangeira, envolvese em dois tipos de comportamento auditivo. Antes de mais, ele precisa de tratar do sinal que chega ao seu ouvido, na forma de uma série de pistas acústicas que têm de ser traduzidas primeiro em fonemas da língua-alvo e, de seguida, em palavras e frases armazenadas no vocabulário do ouvinte, e depois numa ideia abstrata. Esta operação designa-se por descodificação.

É de notar que o ouvinte pode não seguir estas unidades uma após a outra, pelo contrário, pode usar duas ou mais unidades em simultâneo. Um alto grau de automatismo neste processo é a maior diferença que distingue um ouvinte competente de um menos competente: ao associar os grupos de sons às palavras do seu vocabulário, citando Field (2009), um ouvinte competente demonstra as características de rapidez, precisão e sem esforço.

Mas o processo de compreensão oral não acaba por aqui, pois o que o ouvinte consegue extrair a partir da descodificação é apenas o significado literal da mensagem ouvida. Portanto, o ouvinte tem de usar a informação externa para compreender a mensagem, recorrendo ao seu conhecimento do mundo ou ao que é ouvido até ao momento. Trata-se assim de construção de sentido.

No ensino-aprendizagem da compreensão oral da LS/LE, as atividades têm sido desenvolvidas em função dos processos de bottom-up/descodificação e topdown/construção de sentido. No entanto, a prioridade destes dois tipos de processos tem sido muito discutida pelos investigadores. A compreensão oral focada no significado (Meaning-focused listening) privilegia a abordagem de top-down na compreensão oral

\footnotetext{
6 Trecho traduzido: "Como a audição é online, não podemos supor que haja uma progressão fácil de 'bottom-up', de sons para sílabas para palavras para frases. E os usos de 'top-down'de contexto podem servir dois propósitos muito diferentes: para compensar as lacunas na compreensão ou para enriquecer uma mensagem totalmente decodificada" (FIELD, 2009, p. 132, tradução nossa).
} 
(NATION; NEWTON, 2009). Contudo, Nation e Newton (2009) chamam a atenção para a importância do processo de bottom-up na compreensão oral de língua segunda. De acordo com os dois autores Nation e Newton (2009), por um lado, a compreensão pode ser alcançada sem atenção, visto que é possível captar pistas a partir do contexto e reter algumas palavras-chave mesmo sem atender à forma gramatical da mensagem; por outro lado, ainda que a compreensão oral focada no significado seja importante, os aprendentes precisam de ter oportunidades de prestar atenção aos detalhes da língua para que consigam aprender os aspectos do sistema linguístico que podem não ser tão importante para a comunicação básica, mas sim para a precisão da compreensão.

Field (2009) também acrescenta que existem evidências de que os ouvintes menos competentes contam fortemente com o processo a nível de palavras como o ponto de entrada para a interpretação de $L E$, sugerindo a importância das práticas de descodificação na etapa inicial da aprendizagem de LE.

Por conseguinte, nos níveis iniciais da aprendizagem de LE/LS, convém dedicar tempo e esforço a aperfeiçoar o processo de descodificação, a fim de que este se torne mais automático, tal como acontece com os ouvintes nativos, facilitando assim o processo de construção de sentido.

\section{Atividades de compreensão oral}

Atualmente, no que respeita ao formato das aulas de $\mathrm{CO}$, de acordo com Field (2009), as atividades são comumente divididas em três fases: pré-audição, durante a audição e pós-audição.

Antes de pôr em prática a audição, procede-se primeiro à fase de pré-audição. Esta fase tem como objetivo contextualizar a atividade da compreensão oral, pelo que os aprendentes precisam de ter alguma ideia sobre o conteúdo do áudio, formando assim expectativas de $\mathrm{CO}$, como nas situações da vida real. A introdução do tema também ajuda a ativar o interesse e os conhecimentos prévios dos ouvintes para antecipar e fazer previsões sobre o conteúdo do texto que irão ouvir, como foi sublinhado por Rost (2003), Vandergrift (2004) e Richards (2008). Além disso, também é necessário estabelecer os objetivos da $\mathrm{CO}$, uma vez que "different listeners often understand different things from the same text" (BROWN, 1990 apud BUCK, 2001, p. 8)7. Com os objetivos pré-

\footnotetext{
7 Trecho traduzido: "Os ouvintes diferentes compreendem frequentemente coisas diferentes do mesmo texto" (BUCK,
} 
estabelecidos, os alunos conseguem concentrar-se melhor no que é pedido pelos exercícios durante a audição, e não há tanta tendência a perderem-se. Esta fase pode incluir também a explicação do vocabulário, a pronúncia específica de alguma palavra ou a ideia principal do áudio, mas há fatores a ter em conta: alguns professores tendem a ensinar demasiado vocabulário novo ou expandir demasiado a informação contextual (FIELD, 2009), pretendendo garantir a compreensão oral do áudio. Com efeito, reduzem o tempo disponível para a fase de audição, diminuindo a possibilidade de reproduções múltiplas ou a investigação das respostas dos aprendentes.

A fase de audição foca-se na compreensão do áudio, com recurso a qualquer atividade visível que os ouvintes realizam para demonstrarem e monitorizarem a compreensão oral em curso (ROST, 2003). Frequentemente, os professores usam exercícios com perguntas para verificar a compreensão. As questões pré-definidas constituem uma forma de orientar a atenção e a compreensão dos ouvintes. Neste processo, a natureza da CO torna a intervenção do professor impossível. Como tal, a preparação desta fase é mais problemática para os professores porque se trata de planejar uma tarefa que envolve apenas a leitura ou a escrita (ROST, 2003).

Durante a audição, os áudios podem ser reproduzidos duas ou três vezes conforme as tarefas e as necessidades dos aprendentes. Field (2009) atesta que, embora nas situações comunicativas reais os ouvintes não tenham a oportunidade de ouvir duas vezes, eles dispõem das pistas visuais (p.e. expressões faciais e gestos) e ambientais, assim como da possibilidade de pedir a clarificação sobre o elemento que não foi compreendido. Assim sendo, a reprodução múltipla pode complementar essa insuficiência de pistas e ajudar os ouvintes, sobretudo os mais fracos, a confirmar o que ouvem na primeira vez, ou a compreenderem o que não tinham percebido. Após a audição, o professor pode verificar as respostas das perguntas com os alunos.

A fase de pós-audição está relacionada com outros domínios, nomeadamente falar, ler e escrever. $O$ professor pode orientar os alunos para prestarem atenção ao conhecimento funcional e ao vocabulário do texto. Aconselha-se uma última reprodução do áudio, acompanhado da leitura da transcrição. Isso ajuda os alunos a concentraremse em características fonológicas das palavras do texto $(\mathrm{GOH}, 2008)$, bem como em vocabulário novo e na estrutura linguística, promovendo assim a consciência linguística 
(ROST, 2003). Também se pode realizar atividades de escrita e oralidade com o intuito de incentivar o output dos alunos com base na compreensão do input (ROST, 2003), estimulando o uso dos novos conhecimentos adquiridos na prática. Rost (2011, p. 152) afirma que "speaking ability will tend to emerge naturally as a result of extensive work with authentic listening input" ${ }^{\prime \prime}$. Assim, podemos aproveitar a atividade de CO para promover outras competências, com particular destaque para a expressão oral, reforçando a eficiência da aprendizagem de LS/LE.

\section{Materiais autênticos e criados para o desenvolvimento da compreensão oral}

A Abordagem Comunicativa ao ensino de línguas que se tem desenvolvido a partir da década de 70 do século XX tem como base a função comunicativa. Sob esta influência, a autenticidade dos materiais didáticos passa a ser muito valorizada nas aulas de línguas, visto que este tipo de materiais corresponde às características intrínsecas da língua e ao seu uso real nas situações comunicativas do quotidiano.

Em relação à definição da autenticidade de materiais, há divergências sobre este conceito. Vários autores, como Field (2009) e Gilmore (2007), concordam com a definição de Morrow, para quem, "an authentic text is a stretch of real language, produced by a real speaker or writer for a real audience and designed to convey a real message of some sort" (MORROW, 1977 apud GILMORE, 2007, p. 98)9 . A partir desta perspetiva, os textos autênticos, diferentes dos textos para fins didáticos que têm em conta a apresentação de determinado vocabulário ou estruturas linguísticas, podem mostrar as características intrínsecas dos discursos e o uso real da língua nas situações comunicativas. Usando esse critério, é possível saber se um texto é autêntico ou não, através da origem dos discursos e contexto de produção. Sob esta linha de pensamento, no caso da compreensão oral, Field (2009) afirma que as gravações autênticas se referem às gravações em que as pessoas falam de forma natural e sem o propósito de ensino/aprendizagem de língua na mente.

Como os materiais autênticos são retirados dos discursos das situações comunicativas reais para os falantes nativos, constituem uma maior motivação de

\footnotetext{
8 Trecho traduzido: "A capacidade de falar tenderá a emergir naturalmente como resultado de um extenso trabalho com a audição de input autêntico" (ROST, 2011, p. 152, tradução nossa).

9 Trecho traduzido: "Um texto autêntico é um trecho de linguagem real, produzido por um falante ou escritor real para um público real e projetado para transmitir uma mensagem real de algum tipo" (MORROW, 1977 apud GILMORE, 2007, p. 98, tradução nossa).
} 
aprendizagem e fonte de interesse para os aprendentes de línguas. Especialmente os materiais autênticos audiovisuais dispõem de um vasto leque de input para os aprendentes e podem estimular o processamento do cérebro inteiro, o que pode resultar numa aprendizagem mais duradoura (MISHAN, 2005). Desta maneira, a exposição aos discursos autênticos é preferível para os aprendentes de L2 e pode ser benéfica para o desenvolvimento da compreensão oral (VANDERGRIFT, 2002, 2003b; MARESCHAL, 2007 apud VANDERGRIFT, 2007).

A popularização da mídia e Internet permite $o$ acesso a uma grande quantidade $\mathrm{e}$ variedade de recursos de áudios e de audiovisuais. Isso implica também a complexidade da questão da seleção de materiais adequados àquilo que pretendemos. Rost (2001) ainda afirma que poucos dos materiais autênticos podem ser usados na sua forma original, sem reedição e adaptação, sugerindo que o professor precisa decidir a parte do input que mais vale a pena focar. Sobretudo, nos níveis iniciais de aprendizagem, constata-se sempre a dificuldade de encontrar materiais autênticos adequados. Neste caso, cabe ao professor a criação dos materiais. Graças à massificação das Tecnologias de Informação e Comunicação, a criação individual dos áudios e vídeos torna-se numa realidade. Os produtos eletrônicos como câmeras digitais, smartphones, gravador de voz e os produtos de multimídia como programas para edição de áudios e vídeos facilitam aos professores de línguas a produção dos seus próprios materiais.

Ao criar os materiais áudio ou audiovisuais, há alguns fatores particulares a ter em conta. Uma das maiores críticas aos materiais produzidos para fins didáticos é a artificialidade do input, diferente daquilo que ouvimos no quotidiano. Nos manuais didáticos, "as gravações têm o ritmo de fala muito lento, a entoação exagerada e a articulação muito cuidada, recorrendo ao uso padronizado do sotaque (no caso português, regra geral, o sotaque lisboeta)" (FERREIRA, 2019, p. 31). Portanto, mesmo que visem facilitar a compreensão dos alunos, os materiais criados devem tentar aproximar-se dos discursos verossímeis, evitando velocidade de fala demasiado lenta e procurando chegar a um nível de semi-autenticidade. Em função disso, Ur (2013, p. 23) observa que "students may learn best from listening to speech which, while not entirely authentic, is an approximation to the real thing"10.

10 Trecho traduzido: "Os alunos podem aprender melhor ouvindo o discurso que, embora não seja inteiramente autêntico, é uma aproximação à coisa real" (UR, 2013, p. 23, tradução nossa). 


\title{
Implementação da intervenção pedagógico-didática
}

\author{
Contextualização do estágio-pedagógico
}

O estágio pedagógico, inserido no plano do Mestrado em Português Língua Segunda/Língua Estrangeira, teve lugar no Curso Semestral de Português para Estrangeiros ${ }^{11}$ da Faculdade de Letras da Universidade do Porto (FLUP) no ano letivo de 2019/2020, em duas turmas, no nível A1.2, durante dois semestres diferentes. Foram implementadas pela professora estagiária três unidades didáticas. Realiza-se normalmente em modalidade presencial, mas devido à pandemia de COVID-19 em 2020, mudou-se para online entre março, do segundo semestre, até ao final do curso.

A turma do primeiro semestre era constituída por 13 adultos (11 de sexo feminino e 2 de sexo masculino) de diferentes países: Alemanha (1), Argentina/França (1), Coreia do Sul (1), Espanha (3), Equador (1), Estados Unidos da América (1), França (2), Rússia (2), Timor-Leste (1), cujas idades variavam entre os 20 e os 62 anos (com uma média de idades de 37 anos). A turma do segundo semestre era composta por 16 adultos (10 de sexo feminino e 6 de sexo masculino), com a média de idades de 40 anos, tendo o aprendente mais novo 17 anos, e o mais velho 64. Neste grupo, estavam presentes elementos de 12 proveniências: Alemão (1), Chile (1), China (2), Colômbia (2), Dinamarca (1), Espanha (1), Estados Unidos da América (2), Itália (1), Rússia (1), Síria (1), Turquia (1) e Noruega (1). Evidentemente, as línguas maternas dos aprendentes eram muito heterogêneas.

\section{Metodologia}

Considerando o contexto da intervenção pedagógico-didática do presente estudo, isto é, no âmbito do estágio pedagógico supervisionado, foi adotada a metodologia de investigação-ação para orientar o desenvolvimento do trabalho.

Seguimos as quatro fases do modelo de investigação-ação: planejamento,

\footnotetext{
11 O curso tem um total de sessenta horas letivas, dividido em três aulas de noventa minutos por semana. O curso de A1.2 é destinado a estudantes estrangeiros que começam a estudar português e que têm espanhol, italiano ou romeno como língua materna.
} 
execução, observação e reflexão para desenvolver o presente projeto de investigaçãoação.

Como foi referido anteriormente, o objetivo principal da intervenção pedagógicodidática é desenvolver a competência da compreensão oral dos alunos, com recurso aos materiais semi-autênticos. Para realizar o projeto de investigação-ação, elaborámos as seguintes perguntas orientadoras:

i. Há alguns aspetos particulares a ter em conta para levar a cabo as atividades de compreensão oral?

ii. É possível criar materiais semi-autênticos para promover a compreensão oral?

iii. De que forma é que o desenvolvimento da compreensão oral auxilia a aprendizagem de outras competências?

Durante a intervenção pedagógica, procuramos responder a estas perguntas através das atividades concretizadas na sala de aula. Nas unidades letivas, o desenvolvimento da compreensão oral era um fio unificador que ligava todas as atividades. As aulas foram divididas em três partes: pré-atividade, atividade de $\mathrm{CO}$ e pósatividade. Na pré-atividade, realiza-se principalmente a aprendizagem do conteúdo vocabular relativo ao tema e funcionamento da língua, que também serve para contextualizar a atividade de compreensão oral. Durante a atividade da CO, procede-se à audição ou visualização dos recursos de $\mathrm{CO}$ e à realização dos respetivos exercícios. $\mathrm{Na}$ pós-atividade, procura-se promover o output, a partir do input de CO, sobretudo ao nível da interação oral. Nesse sentido, para além da competência de compreensão oral, desenvolvem-se também outras competências durante as aulas.

De forma a apurar os resultados da intervenção pedagógica, recorremos principalmente à observação direta e ao inquérito por questionários. A observação direta assenta na observação do desempenho dos alunos ao longo da realização das atividades. O inquérito, aplicado no final da intervenção de cada regência, inclui questionários com respostas fechadas e abertas, com o intuito de averiguar as opiniões dos alunos relativamente às aulas em geral e aos materiais de CO.

A dimensão colaborativa destacou-se no decorrer do estágio pedagógico. A orientadora do estágio acompanhou todo o processo da intervenção pedagógica da professora estagiária, desde o planejamento das unidades letivas e construção de materiais, até à execução das aulas e reflexão depois da prática letiva, propondo sempre 
sugestões de melhoria e conselhos construtivos. O grupo de estágio também colaborou muito durante este processo, especialmente no sentido da observação das aulas dos colegas estagiários e dos respetivos comentários. Esta colaboração também promoveu a reflexão da professora estagiária sobre as questões relacionadas com a prática letiva.

\section{Descrição de uma unidade didática implementada}

Seguidamente, descreve-se, de forma pormenorizada, uma unidade didática que implementámos, para exemplificar a intervenção pedagógico-didática com base nos pressupostos teóricos anteriores.

A unidade didática, composta por duas unidades letivas de 90 minutos, cujo conteúdo temático principal era a rotina diária, teve como objetivos gerais desenvolver a compreensão e expressão orais, bem como a competência lexical. A esses objetivos gerais correspondem os seguintes objetivos específicos: mobilizar e expandir vocabulário sobre a rotina diária; reter a informação essencial de um vídeo; discriminar informações de um vídeo para escolher as informações correspondentes e falar sobre a rotina diária.

No que diz respeito aos materiais didáticos, tendo em conta a temática, os objetivos e o nível de proficiência do público-alvo, foram construídas fichas de trabalho ${ }^{12}$ que contêm vários tipos de exercícios para orientar a realização das atividades respectivas. Relativamente aos materiais didáticos de $\mathrm{CO}$, trata-se de dois vídeos criados e aproximados aos autênticos, designadamente, "Rotina diária"13 e "Entrevista sobre a rotina diária"14, a fim de tentar mostrar aos aprendentes, tanto quanto possível, as características dos discursos reais da língua-alvo.

\section{Unidade letiva I}

A primeira unidade letiva começou com a interação oral entre a professora e os estudantes sobre as suas rotinas diárias em Portugal, recorrendo a questionário aberto,

\footnotetext{
12 Fichas de trabalho disponíveis em: https://drive.google.com/drive/folders/1t1NIVXU6Jm-FEtr2t181xFIs6QBe4gU?usp=sharing

13 Vídeo disponível em: https://drive.google.com/file/d/1GRLUcslw7LodIRaKYRThVNdI5ow4pV3M/view?usp=sharing

${ }^{14}$ Vídeo disponível em:

https://drive.google.com/file/d/18kQ2xEqQq4NSWpASH51K1ShmhBJUw3DI/view?usp=sharing
} 
como "o que é que costumam fazer no vosso dia a dia?", procurando motivar os interesses dos alunos sobre o tema da aula. De seguida, utilizando como ponto de partida as respostas anteriores, a professora pediu aos alunos, por questionário aberto, para fazerem o levantamento do vocabulário sobre as atividades da rotina diária (de manhã, à tarde, à noite) e registrou-o no quadro, à medida que os alunos indicaram as suas atividades da rotina diária. Esta atividade visou ativar e expandir o repertório vocabular dos alunos, assim como promover a participação ativa dos alunos na aula.

Posteriormente, com vista a aprofundar a competência lexical e funcionamento da língua, foi solicitada aos alunos a resolução em pares de um exercício de construir frases para descrever o dia a dia do José, com base na respetiva banda desenhada. A criação da banda desenhada deveu-se à sua característica de ser divertida e vívida, possibilitando o estímulo da imaginação e motivação de aprendizagem dos alunos. Depois, a professora pediu aos alunos para dizerem as suas propostas em relação à descrição de cada imagem e deu feedback, indicando também as respostas sugeridas, por meio da projeção de slides.

A segunda parte da aula foi dedicada à atividade de compreensão oral, com recurso a um vídeo sobre a rotina diária. Antes de pôr o vídeo, a professora leu com os alunos as instruções escritas do exercício que consistiu em verificar verdadeiro ou falso sobre as informações do vídeo, a fim de garantir a compreensão dos alunos sobre as perguntas. Para a realização deste exercício, os alunos visualizaram uma vez o vídeo, pois com esta visualização pretendeu-se criar uma oportunidade de os alunos se familiarizarem com o vídeo e tentarem perceber a ideia geral do texto. A segunda e a terceira visualizações remeteram para o segundo exercício de preenchimento de espaços em branco, tratando-se de um processo de descodificação do áudio que exige a capacidade de fazer corresponder os sons com as palavras. Feita a visualização, seguiuse a correção dos exercícios, mediante o questionário orientado.

Terminada a fase de audição, os alunos receberam a ficha de transcrição do vídeo, em que houve também uma chamada de atenção para as expressões de frequência de tempo através de uma tabela com advérbios e locuções adverbiais.

Como trabalho de casa, os alunos tiveram de completar uma ficha de trabalho que incluiu um exercício de conjugação dos verbos no Presente do Indicativo, com base num texto de rotina diária, e outro exercício de preenchimento de preposições de tempo. 
A segunda aula foi a continuação da temática da aula anterior, mas devido ao início do confinamento social de COVID-19, essa unidade letiva foi adaptada a ser um trabalho de aprendizagem autónoma em casa e as atividades foram realizadas online. Assim, foram dadas as instruções das tarefas através de Google Classroom ${ }^{15}$.

Para a retoma da aula anterior, os alunos foram solicitados a verificarem as respostas dos exercícios de trabalho de casa, com as soluções disponibilizadas no Google Classroom, onde também puderam colocar perguntas se tivessem dúvidas sobre os exercícios. Depois, a professora esclareceu as respectivas dúvidas.

Em seguida, com o intuito de dar continuidade do tema em questão e desenvolver a competência de compreensão oral dos alunos, procedeu-se a visualização de uma entrevista sobre a rotina diária de dois portugueses, que visou expor os alunos aos discursos autênticos da língua-alvo e aproximar a língua da sala da aula à língua utilizada na vida real. Simultaneamente, mediante um formulário online do Google Forms, foi solicitada aos alunos a resolução de um exercício de compreensão oral, que era composto por exercícios de escolha única e respostas curtas abertas, e para a qual os alunos tiveram de visualizar duas vezes o vídeo. Após a entrega do formulário, os alunos puderam consultar diretamente as correções das perguntas no mesmo formulário. Desta forma, os alunos realizaram e corrigiram os exercícios de forma facilitadora e autónoma, e a professora conseguiu verificar o desempenho dos alunos na tarefa de compreensão oral, através dos dados recolhidos pelo sistema do Google Forms.

Como última tarefa de $\mathrm{CO}$, os alunos tiveram de ler o texto de transcrição do mesmo vídeo e visualizá-lo mais uma vez seguindo a transcrição, o que lhes permitiu observar detalhadamente os aspectos linguísticos orais e compensar algumas possíveis falhas de compreensão oral, por exemplo a identificação de algumas palavras que não tivessem conseguido identificar e associar pelos sons.

A atividade de $\mathrm{CO}$ serviu assim de apoio à realização da atividade de expressão e

\footnotetext{
15 O Google Classroom é um espaço online onde os professores podem gerir os materiais de ensino e criar atividades interativas. Desde o início do semestre, o Google Classroom foi utilizado pela docente e os alunos para partilhar materiais, entregar trabalhos, colocar dúvidas, etc.
} 
interação orais. Para facilitar a realização da interação oral entre os alunos, foi criado um grupo de turma no WhatsApp. Nesta tarefa, os alunos foram distribuídos em pares para fazerem perguntas aos colegas sobre as suas rotinas diárias e respondendo, em seguida, às perguntas colocadas pelos colegas sobre o mesmo. Cada par teve também de apresentar oralmente as semelhanças e diferenças entre si no grupo de WhatsApp. Com esta atividade, pretendeu-se que os alunos transformassem o input que aprenderam na última atividade de CO no output de expressão oral, consolidando assim os novos conhecimentos linguísticos. Depois das exposições dos alunos, a professora estagiária deu feedback aos alunos, sobretudo em termos da correção de alguns erros orais gramaticais mais evidentes.

Por fim, para finalizar esta unidade didática, foi solicitado aos alunos para fazerem uma gravação de vídeo ou áudio, na qual deveriam descrever a sua rotina diária, com o objetivo de consolidarem os conhecimentos adquiridos durante toda a regência e também desenvolverem a expressão oral acerca do tema em questão.

\section{Análise dos resultados da intervenção pedagógico-didática}

Após a lecionação de cada unidade didática, foi aplicado aos alunos um inquérito anônimo por questionários para avaliar a unidade didática em apreço. Os questionários incluem não só a parte acerca da avaliação geral das unidades letivas, como também a parte destinada à avaliação das atividades de CO. Além disso, recorremos à observação direta da professora estagiária e aos comentários da professora orientadora e dos colegas estagiários para complementar a avaliação.

Analisando os dados obtidos, consideramos que, de forma geral, a implementação das unidades didáticas foi bem-sucedida. A maioria dos alunos manifestaram ter gostado das aulas e das atividades de CO. Com base na observação direta na sala de aula, constatamos ainda que os alunos, na generalidade, tinham conseguido realizar as atividades planejadas. Especialmente na unidade letiva II da unidade didática exemplificada, devido ao imprevisto do confinamento social, as atividades tiveram de ser realizadas online. Mesmo assim, os alunos esforçaram-se por completar todas as tarefas, tanto os trabalhos realizados no Google Classroom, como as atividades de expressão e interação orais no WhatsApp. Os recursos áudio e audiovisuais criados mostraram-se adequados ao nível de proficiência dos alunos. Por serem semi-autênticos, conseguiram 
TANG, Y.

também captar a maior atenção dos alunos e assim contribuíram para a realização bemsucedida das atividades de CO.

Posto isto, com base na fundamentação teórica sobre a compreensão oral e nos resultados obtidos da nossa intervenção pedagógico-didática, podemos chegar a algumas conclusões acerca das perguntas orientadoras colocadas no início da investigação.

i. Há alguns aspetos particulares a ter em conta para levar a cabo as atividades de compreensão oral?

Antes de mais, consideramos que a aplicação das três fases de pré-audição, audição e pós-audição constitui um fator crítico para a realização bem-sucedida da atividade de compreensão oral. Sobretudo as atividades realizadas na fase de préaudição, tais como a contextualização do tema, a aprendizagem do vocabulário relevante e a explicação clara das instruções das tarefas, podem facilitar de forma significativa a compreensão oral dos materiais que se seguem. Durante a audição, tendo em conta as características da compreensão oral na vida real e as limitações da compreensão na sala de aula, é necessária a múltipla reprodução dos áudios e audiovisuais. Ao construir os exercícios, o professor deve equilibrar a relação entre o processo de descodificação/bottom-up e o processo de construção de sentido/top-down, sendo que cada um envolve diferentes focos de audição. Por fim, na fase de pós-audição, a transcrição dos textos orais demonstrou ser útil para a construção de um sentido mais completo sobre as informações ouvidas.

i. É possível criar materiais semi-autênticos para promover a
compreensão oral?

Ao longo do nosso projeto foi criado um conjunto de áudios e materiais audiovisuais para os alunos do nível A1.2, que pretenderam aproximar-se dos discursos verossímeis, em termos do vocabulário, pronúncia e ritmo de fala. Com base na análise dos resultados, julgamos que estes materiais contribuíram para a compreensão oral dos alunos. Portanto, a resposta é afirmativa. Mas há alguns pontos a ter em conta ao criar os materiais semi-autênticos. Antes de mais, os materiais devem adequar-se ao nível de proficiência do público-alvo. É de notar que os materiais também não podem ter características demasiado artificiais só para facilitar a compreensão, por exemplo, usar uma pronúncia demasiado clara e ritmo de fala demasiado lento, como se verifica em muitos manuais destinados aos níveis iniciais de aprendizagem. De resto, é preciso ter 
em consideração o tema em causa, a relevância do conteúdo, as implicações culturais, entre outros. Este último aspeto revela-se particularmente importante quando estamos perante um público-alvo com diferentes contextos socioculturais.

i. De que forma é que o desenvolvimento da compreensão oral auxilia a aprendizagem de outras competências?

No nosso projeto de investigação, aplicámos um modelo de aula centrada na compreensão oral, isto é, pré-atividade para promover a competência lexical e funcionamento da língua, atividade de compreensão oral e pós-atividade para desenvolver a expressão e interação oral. Os resultados demonstram que este delinear da realização de atividade é muito coerente e produtivo, pois a pré-atividade proporciona bases de conhecimento linguístico para a atividade de compreensão oral e por sua vez, o input da compreensão oral promove o output a nível da expressão e interação oral. Portanto, através das atividades de compreensão oral, a competência lexical, a expressão e interação oral também foram desenvolvidas. Sintetizando, na abordagem didática de compreensão oral, também se pode desenvolver outras competências, sobretudo a competência linguística, a expressão e interação oral, através de diferentes fases de atividades ou mediante os conteúdos do input.

\section{Conclusão}

A compreensão oral, como uma competência fundamental para a comunicação, necessita de uma abordagem específica e pertinente no ensino-aprendizagem de PLS. 0 presente projeto de investigação-ação, realizado no âmbito do estágio pedagógico do Mestrado em Português Língua Segunda/Língua Estrangeira, pretende desenvolver a competência de compreensão oral dos aprendentes de PLS, com recurso a materiais semi-autênticos. Para este efeito, realizámos a revisão da literatura sobre aspetos relevantes no que diz respeito à compreensão oral e aos materiais autênticos de compreensão oral. Partindo destes princípios teóricos, foi implementado um plano de intervenção pedagógico-didática. Por fim, podemos concluir que os resultados da intervenção pedagógico-didática demonstram ser muito positivos e os nossos objetivos deste projeto de investigação-ação foram atingidos.

Apesar disso, constatamos que existiram algumas limitações na realização deste trabalho. Em termos do desempenho da compreensão oral, por serem implementadas 
apenas três unidades didáticas, não conseguimos avaliar a progressão dos alunos a nível de compreensão oral através da nossa prática letiva. Espera-se que no futuro surjam mais investigações que contribuam para o estudo da competência da compreensão oral em Português Língua Segunda/Língua Estrangeira.

\section{Referências}

BUCK, Gary. Assessing listening. Cambridge: Cambridge University Press, 2001.

BROWN, Gillian. Listening to spoken english. $2^{\text {nd }}$ ed. Harlow: Longman Group UK Ltd, 1990.

FERREIRA, Daniel André Marques. Prática das subcompetências orais para 0 desenvolvimento da competência comunicativa em situações da vida quotidiana: estudo de caso na Universidade de Valência. 2019. Dissertação (Mestrado em Português Língua Segunda/Língua Estrangeira) - Universidade do Porto, Porto, 2019.

FIELD, John. Listening in the language classroom. Cambridge: Cambridge University Press, 2009.

GILMORE, Alex. Authentic materials and authenticity in foreign language learning. Language Teaching, Cambridge, v. 40, n. 2, p. 97-118, 2007.

$\mathrm{GOH}$, Christine. Metacognitive instruction for second language listening development: theory, practice and research implications. RELC Journal, Singapore, v. 39, n. 2, p. 188213, 2008.

RICHARDS, Jack C. Teaching listening and speaking: from theory to practice. Cambridge: Cambridge University Press, 2008.

LEIRIA, Isabel. Português língua segunda e língua estrangeira: investigação e ensino. Idiomático - Revista Digital de Didáctica de PLNM, [s. I.], n. 3, p. 1-11, 2004.

MISHAN, Freda. Designing authenticity into language learning materials. Bristol and Portland: Intellect Books, 2005.

NATION, I. S. P.; NEWTON, Jonathan M. Teaching ESL/EFL listening and speaking. New York: Routledge, 2009.

NUNAN, David. Approaches to teaching listening in the language classroom. In: KOREA TESOL CONFERENCE, 1997, Kyoung-ju. Proceedings [...].: Korea TESOL, 1997. p. 1-10.

NUNAN, David. Listening in language learning. Methodology in Language Teaching: An Anthology of Current Practice, Cambridge, p. 238-241, 2002.

ROST, Michael. Listening tasks and language acquisition. In: JALT CONFERENCE, 2002, Tóquio. Proceedings [...].Tóquio: The Japan Association for Language Teaching, v. 25, p. 18-28, 2002. 
ROST, Michael. Teaching and researching listening. $2^{\text {nd }}$ ed. Harlow: Pearson Education Limited, 2011.

UR, Penny. Teaching listening comprehension. Cambridge: Cambridge University Press, 2013.

VANDERGRIFT, Larry. Listening to learn or learning to listen?. Annual Review of Applied Linguistics, Cambridge, v. 24, p. 3-25, 2004.

VANDERGRIFT, Larry. Recent developments in second and foreign language listening comprehension research. Language Teaching, Cambridge, v. 40, n. 3, p. 191-210, 2007.

Submetido em: 23 set. 2021. Aceito em: 22 out. 2021. 